\title{
DOES SIZE MATTER IN THE DIGITAL AGE? REAPPRAISAL CONSIDERATIONS FOR SYLLABI
}

\author{
BY DANIEL W. NOONAN
}

\begin{abstract}
In the era of digital documents, does size matter? Do we collect digital records more readily than their physical counterparts simply because we can, because we perceive storage to be inexpensive and unlimited? If collection size does not matter in the digital world, what should be considered in determining whether or not to acquire a collection that experiences significant annual growth? College and university archives are charged with collecting, preserving, and providing access to the documentary heritage of their institutions. The central task of higher education-teaching - is very difficult to document; who taught what course can be recorded easily, what was actually taught and how it was taught is much more difficult. The syllabus, a key record to documenting this educational process, has often not been included in archival collections due to intellectual property issues and sheer volume. This article examines the issues that surround collecting syllabi as an exemplar of collecting large volumes of records because we can in the digital age.
\end{abstract}

\section{Introduction}

The general rule of thumb is that most institutional archives collect only about 5 to 10 percent of the records created or received in the course of the business of their institutions. This is in part due to the perception that not all information contained within documents is equally valuable, as well as the fact that an institution has finite resources - money, physical space, personnel - to appropriately process, preserve, and provide access to archival records. However, in the era of digital documents, does size matter? Do we collect because we can — or think we can because we perceive storage to be inexpensive and unlimited? Is value added by collecting records series that we may not have in the past—or at best only sampled — due to their sheer volume? Does collecting and providing access to large bodies of records allow us to more fully document aspects of our institutions that have proven difficult to document in the past? If size does not matter in the digital world, what should be considered in determining whether or not to acquire a collection that experiences significant annual growth?

The central tasks of higher education — teaching and learning — are very difficult 
to document; who taught what course can readily be captured in institutional records, but the record of what was actually taught, and how, let alone how students actually learned, is much more difficult to preserve. Curriculum records, such as syllabi, can provide valuable information for historical research about the development of disciplines and the mission of teaching. ${ }^{1}$ One of the chief reasons that it has historically been difficult to document these tasks is the sheer volume of the records. One can presume that the resources required to store, process, preserve, and provide appropriate access outweighed the potential research value of archiving these records.

My institution, The Ohio State University (Ohio State), like most colleges and universities in the digital era, utilizes an electronic learning management system (LMS) to manage its day-to-day curriculum needs. An LMS can ". . . automate and standardize those elements of the higher education mission that have been the subject of refinement and protection for nearly a millennium.." ${ }^{2}$ The elements that an LMS can provide may include collaborative workspaces and tools for students and faculty to interact throughout a course.

Consider that, historically, Ohio State has been able to maintain only fragmentary documentation of its teaching mission, such as publications (course catalogs), minutes of Ohio State's Council on Academic Affairs, course proposals, and faculty papers (of which we collect less than 1 percent of all faculty members). Ohio State offers more than 10,000 courses per year and has never sought to collect analog/paper versions of syllabi. At 40 to 60 cubic feet per year, this would take up valuable storage space and likely provide only limited access for researchers. In this digital era, documents like the syllabus are created electronically through word processing or an LMS tool. This same 40 to 60 cubic feet of paper would fit on approximately two CDs or one-third of a DVD, and appropriate metadata would allow for a multitude of ways to access the records. ${ }^{3}$ Therefore, an LMS, an enterprise document management system (EDMS), and/ or an institutional repository offers the potential of capturing much more information and documentation about the teaching and learning processes. What if we collected, preserved, and provided access to information, such as syllabi, retained in one of these systems for future dissemination, data mining, and research into understanding and improving the university's educational practices, as a tool for studying pedagogical trends, and, as an added benefit, more fully documenting institutional history?

This cannot be accomplished solely with technological solutions. Issues of appraisal, policy, intellectual property, and privacy, and strategies for preservation are also challenges that must be addressed. While it is tempting to pursue the collecting of other information and documentation pertaining to the learning process - threaded discussions, instant messaging, class blogs, chat rooms, and grade books - the size of student populations (ironically in light of the topic of this article) and, more important, issues of the Family Educational Rights and Privacy Act (FERPA) make this impractical at this time. ${ }^{4}$

Therefore, the focus of this article has been narrowed to preservation of the course syllabus, a document that establishes an expectation of what an instructor is to teach and what a student is to learn and perform. While the course syllabus does not document what faculty members actually do in the classroom, only what they say they will do, we do know that they have communicated this intention to the students in writing. ${ }^{5}$ 


\section{Syllabus Defined}

The Oxford English Dictionary defines a syllabus as ". . . a statement of the subjects covered by a course of instruction or by an examination, in a school, college, etc.; a programme of study." " Jack Gifford suggested that a syllabus is somewhat more complex than that, "... the syllabus has existed since the beginning of communal mankind ... [and that it] . . . is the outcome of curriculum development and contains both an instructional plan and details of the instructional process to be used in a defined unit of study." 7

Curriculum is developed by an institution based upon reaction to outside influences and internal collaboration. The most common outside influence on college and university curricula is society's changing vision of what an educated citizen should know. Outside influences may result in curricula that are general in scope and therefore may be similar from institution to institution. However, it is the internal influences - the result of negotiations among academic departments, faculty members, students, and administrators - that make curricula unique to a particular institution. ${ }^{8}$ The syllabus is the mechanism by which the faculty member transforms the conceptual information that defines a course into a practical learning experience. Furthermore, the content of specific courses, as delineated by their syllabi, may be static or may vary greatly based upon their specific disciplines. The syllabus is therefore a further articulation of the institution's educational mission in a very granular sense. Knowing how a subject was taught informs our understanding of the methods and resources used by faculty at a particular institution. Course syllabi can provide researchers with the ability to compare pedagogical approaches to a variety of subjects across disciplines.

\section{Literature Review}

The archival literature does not address syllabi outside a handful of articles dedicated to the collecting of faculty papers. This is not out of the ordinary as the syllabus is a rather specific document type. Frederick Honhart's seminal survey concluded that they are a vital and significant addition to the documentary heritage held by the repository and that collecting faculty papers allows the archives to document the cross section of all institutional jobs, processes, and activities more adequately and comprehensively. While he noted that "Curriculum materials are also commonly found in collections of faculty papers . . ., " he did not specifically address syllabi. ${ }^{9}$ Mary Janzen suggested that while syllabi are of ". . . a category of papers whose value is often difficult to determine ... [they] . . may also provide evidence of pedagogy." 10

In a 2002 case study on the value of faculty papers, Tom Hyry et al. identified the issue of the comingling of institutional records and personal papers. They noted that "even though they often contain documents related to the life of the university, faculty papers are treated as collections of personal papers, rather than as record groups belonging to the university archives ..." Is the syllabus an institutional record or a faculty member's intellectual property? The answer to this question has a clear impact upon the university archivist's ability to acquire and provide access to syllabi. 
Tara Laver observed in 2003, "Faculty papers continue to be an area of archival enterprise that archivists and manuscript curators find difficult to navigate to their satisfaction, and many archivists question the utility of such collections. A perception exists that they are often large, take up valuable staff time and stack space, and return little on that investment in the way of use." 12 If archivists limit the number of faculty papers they collect, they are likely limiting the amount of teaching and pedagogy that are being documented for the institution. The library literature is more prolific regarding syllabi, with a variety of articles that articulate the need to collect syllabi as a means of assessing library users' needs, developing bibliographic instruction, and conducting collection development. However, the librarian's notion of "collecting" typically addresses a short-term administrative need, rather than the long-term maintaining of syllabi for historical research. ${ }^{13}$

Colleen McFarland concluded in 2005 that while it "requires storage space that many of the surveyed archivists do not have. ... It is, however, more important than ever that college and university archivists collect teaching and learning materials." ${ }^{14}$ A decade hence we can consider whether storage space is still an issue.

\section{Why Is it Desirable to Collect Syllabi?}

Do higher educational archivists collect syllabi on a regular basis? At first look, Laver's analysis of the 2001 survey conducted by the Association of Research Libraries (ARL) suggests that the majority of respondents (79 percent) collect syllabi as part of collecting faculty papers. ${ }^{15}$ Those who did not retain such materials indicated they did not because they employed easier ways of documenting curriculum or had other means of collecting syllabi. ${ }^{16}$ However, the study also notes that only 29 percent accept all faculty papers. ${ }^{17}$ Therefore, it is hard to say what percentage of an institution's syllabi actually is collected. What makes this data even less generalizable is that the number of respondents was 24, or less than 20 percent of all ARL institutions.

In a more recent survey, Elizabeth Yakel et al., reporting on the archival implications of the 2006 Census of Institutional Repositories in the United States, found that syllabi accounted for approximately 3 percent of the volume of faculty papers deposited (approximately 0.2 percent of all archival material deposited) in the surveyed institutional repositories. ${ }^{18}$ Once again, it is hard to generalize these percentages as they only pertain to the items in an institutional repository, not to the general collection development habits of the respondents. However, they do give a sense that syllabi are not collected in large quantities, much less on a regular or systematic basis.

Why would it be desirable for archivists to begin to collect the course syllabi of their institutions more systematically, especially when faculty and students too often equate them with an outline of topics, a calendar of dates, and a list of readings? ${ }^{19}$ It could be because syllabi represent a significant point of interaction, often the first, between an instructor and his or her students. ${ }^{20}$ Or that this first interaction also creates an implicit contract between students and instructors. ${ }^{21}$ Some would go even further to suggest that the syllabus constitutes a legal agreement between faculty members and students, binding students and instructor to an educational path. ${ }^{22}$ As Mark Canada suggested, 
"For many, a syllabus is the academic equivalent of an appliance manual. Everyone expects one, but reading it is another matter. A few compulsive sorts may pore over every letter. . . . A syllabus can be much more, however. A well-crafted syllabus can be the beginning of a promise fulfilled and part of the difference between just another course and one that changes lives." 23 Collecting it as an "appliance manual" allows archivists to document the facts of the teaching process; collecting it as a "promise fulfilled" possibly allows archivists to document the intangible nature of the student/ instructor relationship.

Beyond documenting a particular class at an institution at a particular point in time, Marc Parry argued, “. . . syllabi are a potentially valuable source of information ... [that] . . . could shed light on the evolution of fields . . . or help professors develop new courses." ${ }^{24}$ The systematic collecting of syllabi could provide resources for researchers, as well as the parent institution, to conduct longitudinal analysis of what is taught and how it was taught. As an added benefit, it could provide another aggregated source documenting the scholarly impact of authors cited in the syllabi.

With syllabi, for all practical purposes now beginning life as digital objects, what once might have taken up 40 to 60 cubic feet per year on shelves at Ohio State's university archives could now be stored on two CDs or one DVD. Furthermore, those same 40 to 60 cubic feet of hypothetical syllabi likely would not be processed at the item level, making the search and retrieval beyond folder level time consuming. The electronic versions, however, are more likely to be full-text searchable and contain valuable metadata when harvested from an LMS, an EDMS, or a college, school, and/ or departmental computer drive or storage medium.

So maybe we should collect these documents now just because we can. But as Parry recently noted, “. . . gathering and sharing syllabi can be a messy business. Privacy concerns, legal uncertainty, fragmented and inconsistent sharing practices - all present challenges." 25

\section{Challenges of Collecting Syllabi}

\section{Appraisal Considerations}

When considering whether to collect syllabi, archivists must decide whether to treat them as faculty members' property (and collected as part of faculty members' personal papers), or institutional records to be collected as a records series. Collecting syllabi as parts of faculty papers cannot provide a comprehensive collection, nor can the syllabi be as collectively accessible as they would be as institutional records. Syllabi acquired with faculty papers would not be collected on a regular basis, which would defeat the purpose of providing data for longitudinal analysis or citation analysis for authors contained within the syllabi.

Assume for the moment that intellectual property ownership is not an issue. If syllabi are presumed to be institutional records, what appraisal considerations should be taken into account? A syllabus as an institutional record has a short-term primary value that fills an administrative need; so short that its primary administrative use covers one semester or term with a life cycle of approximately six months. However, there 
are secondary evidential uses, such as a student challenging a grade and its relationship to what was to be taught in a course, or for accreditation purposes, which usually require syllabi to be maintained for a longer period from a records management point of view. Furthermore, syllabi have potential secondary evidential and informational value for longitudinal and citation analyses, and even as resources for crafting new or similar courses.

In the past, the costs associated with storage and processing of the sheer volume of all syllabi outweighed any perceived secondary informational value contained in a comprehensive archival collection of syllabi. Even 20 to 30 years ago, if the notion of trying to systematically collect an institution's corpus of syllabi had been considered, it likely would have included a sampling strategy. Now for all practical purposes, syllabi are born digital and can be collected in toto by harvesting them from an LMS, an EDMS, or a college's, school's, and/or department's computer drives or storage media, or via a standardized repository submission process.

\section{Ownership Considerations}

If we desire to archive syllabi as a means of documenting the instructional process at our institutions of higher learning, we must consider whether we have the right to capture these documents automatically, or whether we need the permission of their authors, the faculty. While many faculty members are loathe to share them, for fear of intellectual theft, others find the syllabi to be fairly broadly and abstractly crafted, and would be more concerned with the posting of lectures and lecture notes in an institutional repository.

The educational professional literature regarding syllabi does not shed much light on the concept of intellectual property ownership. The body of work is relatively small and typically discusses how to structure and compose syllabi. ${ }^{26}$ Most of these works do not address the issue of ownership with the exception of Gifford who suggested that, when putting a syllabus on a faculty website, “. . . it is recommended that you place a copyright notation on the home page of your e-syllabus, including the symbol [C], your name, and the statement that this copyright relates to all the materials original to the faculty member and present or linked directly or indirectly to the home page." 27

The issue of ownership has been addressed to some extent in The Chronicle of Higher Education. Jennifer Sinor in 2008 suggested that "to decide that a syllabus is not a made thing, not worthy of protection without regard to market value or aesthetic value, erodes the terrain of the classroom, a terrain with a history of siege." ${ }^{28}$ George Williams, editor of the ProfHacker Blog, noted in a June 2011 open-thread discussion that he gets several requests each year from grad students for copies of his syllabipresumably not those taking his courses as they would already have copies. Williams states that he does not know how to respond: "On the one hand, I don't want to impede a student's interest or learning. On the other, I feel sort of proprietorial about syllabi: it's taken me years to develop them, and I feel some reluctance just freely distributing them." The respondents, in the discussion thread, generally supported the notion of sharing, but that the content of the syllabus is the professor's intellectual property. ${ }^{29}$

If we examine the issue from a copyright point of view as Gifford suggests, most institutions have a policy regarding copyright, and typically it vests ownership in the 
faculty member, whether explicitly or implicitly. The University of Michigan uses the following explicit language as does Kettering University and West Chester University with slight variations:

Ownership Principles . . . all faculty. . . . own and control instructional materials and scholarly works created at their own initiative with usual University resources ... Examples . . . may include, but are not limited to: lecture notes, transparencies, case examples . . . regardless of the media in which the works are produced or the forms of dissemination. University Community Interests - Even though individual faculty own the works described . . . above . . . the University shall be permitted to use materials created for ordinary teaching use in the classroom and in department programs (such as syllabi, assignments, and tests) for administrative purposes, including satisfying requests of accreditation agencies for faculty-authored syllabi and course descriptions. ${ }^{30}$

Other colleges, including Carleton, use implicit language:

The College will retain ownership of the copyright in works that are specifically directed or commissioned by the College or produced by an individual (or group of individuals) as a specific job requirement... This category does not include materials created by faculty in connection with their teaching, research, or other scholarly activities. . . . ${ }^{31}$

North Carolina State University states,

The University owns the following works: (a) Directed Works . . "Directed Work(s)" means a work created within the employment responsibilities of the creator, as a specific work assignment, with sponsored or external funds administered by the University, or with the Exceptional Use of University Resources. However, a faculty member or student's general obligation to produce scholarly works or teach courses does not constitute a Directed Work. . . . Instructional materials or courseware created by faculty members required to teach courses as part of their employment responsibilities shall not be deemed Directed Works. ${ }^{32}$

The University of Illinois, Urbana-Champaign has the following implicit policy:

"Traditional academic copyrightable works" are a subset of copyrightable works created independently and at the creator's initiative for academic purposes. Examples may include class notes, books, theses and dissertations, educational software (also known as courseware or lessonware) that the creators may design for courses they teach, . . ${ }^{33}$

My own institution's copyright policy is managed by the Technology Commercialization Office and can be categorized as "implicit" in regard to syllabi ownership. It states that "copyright in most books, papers, artistic works, etc., will belong to their individual authors (creators), but this does not extend to material contained in such works to which the University has independent rights . . . nor to works produced as an integral part of a sponsored program or other specific responsibility. . . . It is not intended that this Policy change the traditional relationship between the University and faculty authors of textbooks and other scholarly and artistic works." 34

An aspect of ownership mentioned earlier is that of a covenant or contract. 
Increasingly, the contemporary syllabus is becoming more like a legal document, an implied student-teacher contract that has grown ever more literal, down to a proliferation of fine print and demands by some professors that students must sign and attest that they have read and understood. ${ }^{35}$ This echoes Ken Matejka and Lance B. Kurke's notion more than two decades ago that ". . . it is entirely possible to make a syllabus a binding agreement by having the last page be a brief contract: 'I have read this syllabus, understand its implications ... and will abide by it." ${ }^{\prime 36}$

If this were medieval Europe and the faculty itinerant independent instructors, then this covenant or contract would clearly establish the owner of the intellectual property of the syllabus as the faculty member. ${ }^{37}$ However, in the modern college or university, is this covenant or contract established between the student and the instructor, the student and the institution, or the student and the instructor as a "work for hire" within the institution? In the first situation, like the itinerant instructor, the faculty member would own the syllabus outright, while in the latter two it would appear that the institution would either own it outright or have a stake in the ownership.

Furthermore, consider that an institutional template more often than not dictates the structure of a syllabus, requiring certain elements and departmental/unit review for compliance and completeness.

Jay Parkes, University of New Mexico, suggested that "Among the syllabus's primary functions . . . is [that of] a permanent record within and across an institution." ${ }^{38} \mathrm{Ad}-$ ditionally, Richard A. Holmgren, Allegheny College, noted that accreditation agencies, such as Middle States, require evidence of course syllabi that incorporate expected learning outcomes. ${ }^{39}$ This implies institutional ownership. Many examples suggest syllabi are treated as institutional records:

- Syracuse University requires course descriptions and syllabi to be retained for "Current academic year plus 7 years" and notes, "Academic departments may want to designate selected course descriptions/syllabi as historically significant and send the records to Archives for permanent retention if the course is cutting edge, employs new teaching methodology, or reflects a change in the department's development." ${ }^{40}$

- The State of New Jersey requires four-year colleges and universities to retain syllabi "until updated." 41

- Ohio State has a record series that is part of the General Records Retention and Disposition Schedule, "Course Syllabi; Retain -10 years; Disposition-Destroy; Notes: The Archives retains course descriptions published in catalogs and bulletins permanently. ${ }^{* 2}$

There is a tension between faculty perception of their intellectual property rights and a policy to maintain syllabi as official records of the institution. However, a well-crafted copyright and/or intellectual property policy — such as the aforementioned policies of the University of Michigan, Kettering University, and West Chester University-that explicitly outlines ownership rights and roles would allow institutional archives to collect and preserve syllabi in a more systematic manner. 


\section{How to Collect}

As suggested above, an institution could employ three basic strategies for archiving syllabi: harvest syllabi from the learning management system; collect them directly from college, school, department, or unit as appropriate; or use a standardized enterprise document management system or institutional repository submission process. Each strategy has its strengths and weaknesses. Working with campus information technology partners to identify and harvest syllabi from an LMS would provide a "one-stop-collecting" solution. However, syllabi live in these systems in a variety of ways. They may be documents in a word processing format or converted to PDFs; they may be HTML documents within the system; they may be created utilizing a system's syllabus tool; or they may be some other format altogether. Furthermore, they may not even be included in the learning management system, and, if they are, the file naming conventions are likely to be all over the board. Therefore, comprehensively collecting the institution's corpus of syllabi is unlikely in this manner.

Generally, the colleges, schools, departments, or other units in a teaching institution require the submission of syllabi by their faculty members each time a course is taught. Most often, a template contains required sections for contact information, course description, objectives, teaching strategy, text and assigned readings, student responsibilities, grading rubric, assignments, and special notices regarding registration, academic misconduct, technological competencies, disabilities, and incomplete grades. These unit copies are more likely to be consistently constructed and uniformly maintained, and could be more effective means of comprehensively collecting an institution's syllabi. The archives could advise units on the use of consistent file formats and file naming conventions to further facilitate this process. However, nothing guarantees that, even if the syllabi are born digital, they are submitted digitally to or are maintained digitally by the unit. Additionally, achieving a comprehensive collection is complicated by having to collect from multiple sources and potentially at multiple levels of institutional hierarchy.

The third approach is to develop and implement a standardized EDMS or institutional repository submission process. This is clearly a significant collaborative undertaking that requires buy-in at the highest levels. In lieu of submitting a syllabus to the college, school, department, or unit prior to the term, faculty members would create syllabi in a standardized template as part of a document management workflow that would capture appropriate metadata and save it in an appropriate preservation format. The submission process could feed an institution's document management system, from which it could be later harvested to a preservation environment, or could be simultaneously submitted to the preservation repository. Either way, syllabi would be accessible to faculty members, their students, and the institution's administration. The document management system option may be desirable for two reasons: to restrict access while a syllabus is an active document and to allow for revisions throughout the term.

Some institutions are creating digital syllabi repositories. While not comprehensive, the University of Michigan's Kresge Business Administration Library provides a twoacademic-year repository of syllabi for the students of the Ross School of Business. ${ }^{43}$ An early career faculty group at the Metropolitan College of Denver in late 2010 
created a wiki for annotated syllabi, which ". . . are living artifacts that begin with a simple course syllabus and then grow in scope and depth as annotations and links . . . are added. . . . The annotated syllabus is an ideal format for prompting the reflection that goes into course design and for fostering a systematic approach to instructional growth and development." 44 This example clearly supports the concept of collecting syllabi for their secondary values.

On a grander scale is the Open Syllabus Project (OSP) founded in 2014, which “. . . is an effort to create the first large-scale online database of university course syllabi as a platform for the development of new research, teaching, and administrative tools ... [that] . . could enable new lines of inquiry into canon formation, the evolution of disciplines, pedagogical change, and institutional history. . . . It could introduce new metrics into the conversation about scholarly communication, from tracking the use of open-access publications to measuring how frequently, and in what contexts, faculty members' works are taught." 45 The project acknowledges prior attempts to archive syllabi from the H-Net (www.h-net.org) and MIT OpenCourseWare (ocw.mit.edu) projects, to Daniel J. Cohen's now defunct Syllabus Finder. ${ }^{46}$ Cohen, an OSP advisory board member, observed in 2005, "The proliferation of syllabi on the Web presents for the first time the possibility of gaining a comprehensive picture of how history survey courses are taught and how textbooks are used in them . . . in 2002 I wrote some experimental software, now called the Syllabus Finder, to locate, scan, and store syllabi from the Web. Thus far the software has found and tagged over three hundred thousand syllabi ... [and] ... allows one to look up courses on specific topics, narrow or broad, to examine how history is taught at thousands of educational institutions, and to see which courses assign a certain primary or secondary source. ${ }^{947}$ All of these projects demonstrate a demand for the collection, preservation, and access to course syllabi.

\section{The Final Challenge: Feasibility}

Today, syllabi are born digital and can be collected in toto by harvesting from an LMS; an EDMS; a college's, a school's, and/or a department's computer drives or storage media; or via a standardized repository submission process. Technology's evolution does provide archivists with a means of collecting a significantly greater amount of documentary heritage. Potential also exists for improved avenues of access and analysis. Mayer-Schönberger and Cukier suggested that ". . . sampling comes with a cost that has long been acknowledged but shunted aside. It loses detail . . . a shift is taking place from collecting some data to gathering as much as possible, and if feasible, getting everything: $\mathrm{N}=$ all . . . [it] . . means we can drill down deep into data; samples can't do that nearly as well." ${ }^{48}$ Two key words in Mayer-Schönberger and Cukier's quote are "if feasible." While this is all possible, the final challenge archivists need to grapple with is the feasibility of collecting because we can.

Clearly, there is the potential to harvest from an LMS, EDMS, or departmental/unit share drive, or to provide a process for standardized deposit into an institutional repository. However, this may require the deployment of additional software, which, even if it is open source is not actually free. It unquestionably requires the development of 
workflows that may be complex by personnel or consultants who are not inexpensive. While storage is relatively inexpensive, it is not free; hardware does cost real money, and quality hardware for preservation purposes may be expensive. Whatever the storage capacity projections are, they must always be doubled for backup and disaster recovery purposes, and hardware should be replaced approximately every five years. And this does not even account for the eventual cost of migrating formats and preservation platforms. Finally, should an archivist determine that it is not feasible within his or her institution, the option still exists of using a resource like the Open Syllabus Project or other collaborative project. However, similar feasibility caveats, as well as questions of project sustainability, come with these solutions.

Is it technologically possible? Yes. Is it feasible? Maybe.

\section{Conclusions}

Should archivists collect a large corpus of records they previously did not, because it is now technologically possible? The answers can be found in the basics of the archival process. What value do the records provide from a primary evidential point of view? What potential secondary research value do they provide? What issues of ownership, privacy, and other concerns should be considered? And, last, while technologically we likely can collect large corpuses like syllabi, archivists need to determine if it is feasible for their institutions.

In the example discussed in this article, archiving syllabi as a means of documenting the evolution of what is taught and providing resources for longitudinal analysis of how courses are taught at colleges and universities is a desirable activity. It has the added benefit of providing an aggregated source documenting the scholarly impact of authors cited in the syllabi. Today, we have better capacity to collect, preserve, and provide access to syllabi than when they were created as analog records. Institutions need to consider their local intellectual property ownership policies before embarking on a full-scale project to archive all syllabi. To create the most comprehensive syllabi collection, the most effective approach is to treat them as institutional records-intellectual property ownership permitting - as opposed to collecting them as part of faculty papers, by developing a centralized, standardized approach to systematically capture syllabi as born-digital documents. Should an institution not have the capacity but the desire to encourage the archiving of its faculty's syllabi, it could promote the use of nascent tools such as the Open Syllabus Project.

A feasible and effectively designed means to capture, preserve, and provide access to syllabi is certainly an example not only of collecting now because we can, but of providing value in doing so 
ABOUT THE AUTHOR: Daniel W. Noonan, assistant professor, is the electronic records/digital resources archivist for The Ohio State University. He received his MLS from Rutgers University in 2001. Reporting to the university archivist, he assists in the implementation and maintenance of the university's records management policy and program. This includes retention schedule development and providing consultation and training pertaining to electronic records retention, management and disposition, document conversion, and electronic records and digital assets preservation. He works within the University Libraries on projects to ensure that there is a robust infrastructure and metadata framework for managing archival electronic university administrative records and other digital objects. And he collaborates with the Office of the CIO to develop and maintain an information architecture framework for enterprise content management, including the development of project management and audit tools that address the recordkeeping aspects of electronic administrative systems.

\section{NOTES}

1. Helen Willa Samuels, Varsity Letters, Documenting Modern Colleges and Universities (Chicago: The Society of American Archivists and Metuchen, NJ: Scarecrow Press, 1992), 58-64.

2. Richard N. Katz, "Balancing Technology and Tradition: The Example of Course Management Systems," EDUCAUSE Review 38, no. 4 (2003): 54.

3. Assume the average syllabus is 10 to 15 pages in length and approximately 100 to150KB in size. With 10,000 courses, this equals 100,000 to 150,000 pages or $1,000,000$ to $1,500,000 \mathrm{~KB}$ (975 to $1,500 \mathrm{MB}$ or 1 to $1.5 \mathrm{~GB})$. On average, a cubic-foot record storage box can accommodate 2,500 pages. CDs store 700MB, and DVDs store 4.7GBs.

4. US Department of Education, "The Family Educational Rights and Privacy Act (FERPA)," accessed December 3, 2014, www2.ed.gov/policy/gen/guid/fpco/ferpa/index.html. FERPA (20 U.S.C. § $1232 \mathrm{~g}$; 34 CFR Part 99) is a federal law that protects the privacy of student education records. The law applies to all schools that receive funds under an applicable program of the US Department of Education.

5. Jay Parkes, Tracy K. Fix, and Mary B. Harris, "What Syllabi Communicate about Assessment in College Classrooms," Journal on Excellence in College Teaching, no. 1 (2003): 61.

6. Oxford English Dictionary, s.v. "syllabus," www.oed.com. (Requires subscription.)

7. Jack Gifford, The Syllabus/E-Syllabus for the 21st Century (Lanham, MD: University Press of America, 2003), 3.

8. Samuels, Varsity Letters, 54-55

9. Frederick L. Honhart, "The Solicitation, Appraisal, and Acquisition of Faculty Papers," College and Research Libraries 44, no. 3 (1983): 240-41.

10. Mary E. Janzen, "Pruning the Groves of Academe: Appraisal, Arrangement and Description of Faculty Papers," Georgia Archives 9, no. 2 (1981): 35.

11. Tom Hyry, Diane Kaplan, and Christine Weideman, “"Though This Be Madness, yet There Is Method in 't': Assessing the Value of Faculty Papers and Defining a Collecting Policy," The American Archivist 65, no. 1 (2002): 57.

12. Tara Zachary Laver, "In a Class by Themselves: Faculty Papers at Research University Archives and Manuscript Repositories," The American Archivist 66, no. 1 (2003): 160.

13. Examples include Rick Bean and Lynn M. Klekowski, "Course Syllabi: Extracting Their Hidden Potential," Sixth Off-Campus Library Services Conference Proceedings, Kansas City, Missouri, October 1993 (Mount Pleasant: Central Michigan University, 1993); Linda K. Rambler, "Syllabus Study: Key to a Responsive Academic Library," Journal of Academic Librarianship 8, no. 3 (1982): 
155-56; Jeremy W. Sayles, "Course Information Analysis: Foundation for Creative Library Support," Journal of Academic Librarianship 10, no. 6 (1985): 343-45; Cindy Shirkey, "Taking the Guesswork Out of Collection Development: Using Syllabi for a User-Centered Collection Development Method," Collection Management 36, no. 3 (2011): 156-64; Amy VanScoy and Megan J. Oakleaf, "Evidence vs. Anecdote: Using Syllabi to Plan Curriculum-Integrated Information Literacy Instruction," College and Research Libraries 69, no. 6 (2008): 566-75; Adam E. Haigh, "You Can Lead Students to the Library, but Can You Make Them Do Research? The Effect of Syllabus Design and Content on Undergraduates' Perceptions and Use of the Academic Library," Journal of Business and Finance Librarianship 18 (2013): 33-48; and Rachael E. Elrod, Elise D. Wallace, and Cecilia B. Sirigos, "Teaching Information Literacy: A Review of 100 Syllabi," Southeastern Librarian 60, no. 3 (2012): $8-15$.

14. Colleen McFarland, "Documenting Teaching and Learning: Practices, Attitudes, and Opportunities in College and University Archives," Archival Issues 29, no. 1 (2005): 33.

15. Association of Research Libraries, Membership, accessed December 17, 2014, www.arl.org/arl/ membership/members.shtml. ARL is a nonprofit organization of 126 research libraries at comprehensive research institutions in the United States and Canada that share similar research missions, aspirations, and achievements. ARL ". . . operates as a forum for the exchange of ideas and as an agent for collective action."

16. Laver, "In a Class by Themselves," 174.

17. Ibid., 168.

18. Elizabeth Yakel, Soo Young Rieh, Beth St. Jean, Karen Markey, and Jihyun Kim, "Institutional Repositories and the Institutional Repository: College and University Archives and Special Collections in an Era of Change," The American Archivist 71, no. 2 (2008): 348.

19. Howard B. Altman, "Syllabus Shares 'What the Teacher Wants,"” The Teaching Professor 3, no. 5 (1989): 1.

20. Judith Grunert, The Course Syllabus A Learning-Centered Approach (Bolton, MA: Anker Publishing Company, 1997), xi.

21. Richard Fraher, "Learning a New Art: Suggestions for Beginning Teachers," in The Art and Craft of Teaching, ed. Margaret Morganroth Gullette (Cambridge, MA: Harvard University Press, 1984), $119-20$.

22. Altman, "Syllabus Shares 'What the Teacher Wants," 1.

23. Mark Canada, "The Syllabus: A Place to Engage Students' Egos," New Directions for Teaching and Learning 135 (2013): 37.

24. Marc Parry, "New Syllabus Archive Opens the "Curricular Black Box,"” The Chronicle of Higher Education, March 25, 2014, accessed November, 6 2014, chronicle.com/blogs/wiredcampus/newsyllabus-archive-opens-the-curricular-black-box/51285.

25. Parry, "New Syllabus Archive Opens the "Curricular Black Box."

26. Examples include Malcolm A. Lowther, Joan S. Stark, and Gretchen G. Martens, Preparing Course Syllabi for Improved Communication (Ann Arbor, MI: The National Center for Research to Improve Postsecondary Teaching and Learning, 1989) and Larry Lovell-Troy and Paul Eickmann, Course Design for College Teachers (Englewood Cliffs, NJ: Educational Technology Publications, 1992).

27. Gifford, The Syllabus/E-Syllabus for the 21st Century, 14.

28. Jennifer Sinor, "When a Syllabus Is Not Your Own," The Chronicle of Higher Education 54, no. 48 (2008): A21-A24.

29. George Williams, "Open Thread Wednesday! Sharing Syllabi?," ProfHacker, The Chronicle of Higher Education, June 1, 2011, accessed November 6, 2014, chronicle.com/blogs/profhacker/ open-thread-wednesday-sharing-syllabi/33736. Exemplary responses include mpotter_99's "I think of syllabi as scholarly documents. Whenever we teach, there's (ideally) a tremendous amount of thought, consideration, and intentionality that go into our course design decisions.... Whenever we produce other forms of scholarly products (e.g. articles, book chapters, posters, etc.), we very willingly make them public and share with our peers. Why not treat syllabi similarly?" and Derek Buff's "The acknowledgement issue is a delicate one. We have standard ways to acknowledge the research and scholarship done by others (citations and such), but we don't have any standards or norms around attribution of teaching materials or methodologies. I kind of wish we did, since giving credit where credit is due (a) is generally an ethical thing to do and (b) might result in better institutional recognition of contributions to the teaching profession." 
30. University of Michigan, "University Copyright Policy" (2002), accessed January 8, 2015, www .lib.umich.edu/copyright/university-copyright-policy; Kettering University, "Copyright Policy of Kettering University” (2011), accessed January 8, 2015, www.kettering.edu/sites/default/files/ resource-file-download/KU\%20Copyright\%20Policy.docx; and West Chester University, Model Guidelines for the Use of Copyright Protected Materials (2003), accessed January 8, 2015, www .wcupa.edu/library.fhg/pdfs/Copyright_Guidelines.pdf.

31. Carleton College, "Carleton College's Copyright Policy" (2006), accessed January 8, 2015, apps .carleton.edu/campus/copyright/CopyrightPolicy/.

32. North Carolina State University, "Copyright Regulation-Copyright Implementation Pursuant to Copyright Use and Ownership Policy of the University of North Carolina," accessed January 8, 2015, policies.ncsu.edu/regulation/reg-01-25-03.

33. University of Illinois, The General Rules Concerning University Organization and Procedure (last amended January 24, 2013), accessed October 8, 2015, www.bot.uillinois.edu/sites/bot.uillinois .edu/files/bot-files/General-Rules-1-24-13.pdf.

34. The Ohio State University, Policy on Patents and Copyright Policy, accessed January 8, 2015, tco .osu.edu/wp-content/uploads/2013/09/PatentCopyrightPolicy.pdf.

35. Paula Walsey, "Research Yields Tips on Crafting Better Syllabi," The Chronicle of Higher Education, March 14, 2008, accessed November 6, 2014, chronicle.com/weekly/v54/i27/27a01101.htm.

36. Ken Matejka and Lance B. Kurke, "Designing a Great Syllabus," College Teaching 42, no. 3 (1994): 115 .

37. Katz, "Balancing Technology and Tradition," 50.

38. Parkes, Fix, and Harris, "What Syllabi Communicate about Assessment in College Classrooms," 62.

39. Richard A. Holmgren, executive director of Learning, Information, and Technology Services and director of The Learning Commons, Allegheny College, e-mail to author, May 15, 2008.

40. Syracuse University Records Management, "Syracuse University Records Retention Schedule: Academic Records," accessed March 12, 2015, rm.syr.edu/ret-aca.html.

41. State of New Jersey, Division of Archives and Records Management, Four Year Colleges Records Retention and Disposition Schedule, accessed January 8, 2015, ogc.pages.tcnj.edu/files/2013/09/ Records-Retention.pdf.

42. The Ohio State University, General Records Retention and Disposition Schedule, accessed January 8, 2015, go.osu.edu/general-schedule.

43. University of Michigan, Kresge Business Administration Library, "Search for a Syllabus," accessed February 19, 2015, www.lib.umich.edu/kresge/syllabi/ksaSearch.php.

44. Metropolitan State College of Denver, "Home Page for Annotated Syllabi," accessed February 19, 2015, metrofacultydevelopment.pbworks.com/w/page/33934299/Home\%20Page\%20for\%20Annotated $\% 20$ Syllabi.

45. Open Syllabus Project, "About," accessed February 19, 2015, opensyllabusproject.org/about/.

46. Parry, "New Syllabus Archive Opens the "Curricular Black Box.",

47. Daniel J. Cohen, "By the Book: Assessing the Place of Textbooks in US Survey Courses," Journal of American History 91, no. 4 (2005): 1405-1406.

48. Viktor Mayer-Schönberger and Kenneth Cukier, Big Data: A Revolution that Will Transform How We Live, Work, and Think (Boston, New York: Houghton Mifflin Harcourt, 2013), 26. 